\title{
Profitability Performance of Selected Top Listed Malaysian GLCs and non-GLCs
}

\author{
Nordin Haji Mohamad and Fatimah Said
}

\begin{abstract}
The purpose of this study is to measure and compare the profitability performance of selected top-listed Malaysian companies, both government linked and non-government linked companies. A linear programming based methodology, known as data envelopment analysis, DEAis used to measure the relative performance of each company by utilizing a list of normalized performance indicators for the period 2009-2011. In addition to estimating technical and scale efficiency, DEA also provides a mean of measuring returns to scale - increasing, constant and decreasing - and identifying companies exhibiting the most productive scale size, mpss. The DEA scores indicate that only a small number of the companies were operating on the best-practice frontier under the assumptions of constant and variable returns to scale.Comparisons are made between government-linked and non-government linked companies. Most of the companies showed serious scale inefficiency and exhibited decreasing return to scale.
\end{abstract}

Index Terms-Data envelopment analysis, government linked companies, performance, relative technical efficiency.

\section{INTRODUCTION}

Profitability is the main financial goal of all business activities or ventures. It is usually defined as the ability of a given investment to earn a return on its use. Profitability also determines the survival of the business in the long run. Thus measuring and assessing profitability is very important. In financial study, profitability is normally measured in ratio forms as the return on assets (ROA), return on equity (ROE) and return on revenues or sales (ROS). For most of these ratios, a higher value is indicative that the business is flourishing.

Performance evaluation involves a number of attributes or criteria, both quantifiable and non-quantifiable. Several methods for effective evaluation of performance involving multiple variables have recently been conducted. This includes financial statement analysis [1], [2], balanced scorecard [3], [4], multivariate statistical analysis [5], analytic hierarchy process [6], [7], fuzzy set theory [8], grey relation analysis [9] and data envelopment analysis [10].Among these approaches, DEA is perhaps the most commonly used methodology for measuring performance and efficiency estimation [11].

Manuscript received May 16, 2013; revised July 13, 2013

This work was supported in part by the University of Malaya Research Grant UMRG: 246-12AFR, Profitability Performance of Selected Top-Listed Malaysian GLCs and non-GLCs. Nordin Haji Mohamad and Fatimah Said.

N. H. Mohamad is with Institute of Mathematical Sciences, University of Malaya, 50603 Kuala Lumpur, Malaysia (e-mail: nordinhm@um.edu.my).

F. Said is with the Faculty of Economics and Administration, University of Malaya, 50603 Kuala Lumpur, Malaysia (e-mail: fatimahs@um.edu.my).
DEA does not require specific functional relationship between production outputs and inputs nor any specific statistical distribution of the error terms. Its ability to handle production processes involving multiple inputs and multiple outputs makes it an appealing choice and outweighs its statistical shortcomings. It provides detailed information on the comparative performance of each decision making unit, DMU in the form of an efficiency score (one for efficient DMUs and less than one for inefficient DMUs) which is interpreted as a measure of business performance. For inefficient DMU, DEA identifies its peers from a set of efficient units that it is compared with, as well as improvements in output and/or input levels required by the unit to be on the efficient frontier. In other words, DEA provides the inefficient unit with guidance or path to the frontier. However, DEA provides no statistical information on the goodness and reliability of the results.

This paper investigates the performance of selected largest listed government-linked companies, GLCs and non-government linked companies, non-GLCs in Malaysia using super-efficiency DEA model. The paper unfolds as follows. Second section presents a literature review on selected performance evaluation conducted using DEA model. Section three defines the super-efficiency DEA model utilized in the study. This is followed by an empirical study on 114 largest listed companies (20 GLCs and 94 non-GLCs) by revenue as compiled by Malaysian Business. The final section presents our conclusions and directions for future research.

\section{LITERATURE REVIEW}

Al-Shammari [12] empirically assesses the relative efficiency of profit oriented DMUs, viz. fifty-five Jordanian manufacturing shareholding companies listed in the Amman Financial Market using input and output data for the year 1995. The number of employees, paid-in capital and fixed assets are three input measures utilized for the study, whereas the market value per share, net sales and net income after taxes are three output targets chosen. Out of the sample of 55 companies, $12(21.82 \%)$ were found to be relatively efficient. The relative efficiency score of the 43 inefficient DMUs ranged from 0.127 to 0.911 . The study also illustrates the necessary adjustments in the slack variables in order to achieve Pareto efficiency. Discussions with key executives in selected manufacturing organizations were also conducted. Despite agreeing that DEA provided new insights not available from other methods of assessment and can provide a motivation to the best practicing DMUs, they argued that DEA results cannot be considered as a substitute to the partial profitability ratio measures. 
Another study on measuring the relative market efficiency of sixty-two top listed companies in Egypt was conducted by Mostafa [13] using production frontier approach, PFA (an alternative name for DEA). Two inputs comprising of assets and employees, and three outputs signifying by net profit, market capitalization and share price are chosen as input-output indicators. The efficiency scores under constant return to scale, CRS ranged from 0.2 to 1.0 with an average of 0.39 . Under variable return to scale the scores varied from 0.4 to 1.0 with an average of 0.46 . This indicates that if the average company in the sample is on the most efficient frontier then the average company could realize a 54 percent cost saving. Overall, the results indicate that the performance of several companies is sub-optimal, suggesting the potential for improvements in profitability and marketability. Slack variables are used to identify sources of inefficiency. Among future directions suggested include the utilization of a larger sample size, to test the robustness of the results and cross analysis with traditional efficiency measures such as financial ratio.

Other studies on listed companies include [14], [15]. Ebadi et al. [16] utilize five super-efficiency models in ranking 74 high schools from the north of Iran. It was found that the difference between the results obtained by various alternatives is notsignificant. In this paper we utilize an equivalent Andersen-Petersen [17]super-efficiency model to investigate the relative technical efficiency of selected top listed companies by revenue in Malaysia.

\section{METHODOLOGY}

Following Mohamad and Said [10] the strictly output-oriented DEA model under constant return to scale, CRS utilized to evaluate listed companies activities that allows the inclusion of multiple inputs and outputs in the production frontier is stated as follows

Maximize

$$
\Omega_{0}
$$

subject to

$$
\begin{aligned}
& -X_{0 i}+\sum_{k=1}^{S} X_{k i} \lambda_{k}=0, i=1,2 \ldots n, \\
& -Y_{0 j} \Omega_{0}+\sum_{k=1}^{S} Y_{k j} \lambda_{k} \geq 0, j=1,2 \ldots m,
\end{aligned}
$$

\section{$\lambda_{k} \geq 0, k=1,2, \ldots, S, \Omega_{0}$ unconstrained}

where there are $S$ DMUs to be investigated, each utilizes $m$ inputs denoted by $X_{k}=\left\{X_{k 1}, X_{k 2}, \ldots, X_{k m}\right\}$ to produce $n$ outputsdenoted by $Y_{k}=\left\{Y_{k 1}, Y_{k 2}, \ldots, Y_{k n}\right\}$. The relative technical efficiency, $\theta_{0}$ for $\mathrm{DMU}_{0}$ is defined as $\theta_{0}=1 / \Omega_{0}$.

For evaluation under the assumption of variable return to scale, VRS an additional convexity constraint is imposed on $\lambda_{k}$ such that

$$
\sum_{k=1}^{S} \lambda_{k}=1 .
$$

This results in the formation of a convex hull of intersecting planes which envelope the data points more tightly than the CRS conical hull and thus provides technical efficiency scores which are greater than or equal to those obtained under the assumption of CRS.The difference in the technical efficiency scores under the two assumptions of returns to scale is mainly attributable to scale inefficiency. Thus, scale efficiency, $S E$, can be viewed as the extent to which a DMU can take advantage of returns to scale by altering its size towards the optimal size (defined as the regions in which there are CRS in the relationship between outputs and inputs) and is computed as $S E_{\mathrm{O}}=\theta_{\mathrm{O}}^{C R S} / \theta_{\mathrm{O}}^{V R S} \leq 1$.

Under normal DEA model, inefficient DMUs having unique scores of less than one can be rankedaccording to their scores. But all efficient DMUs are assigned efficiency score of unity (or 100 percent), making it impossible to differentiate their performance. To overcome this problem one alternative procedure known as super-efficient DEA model was proposed by Andersen and Petersen [17] on the traditional DEA model by eliminating the constraint associated with a particular efficient DMU. This relaxation produces efficiency score of greater than or equals to one, thereby making it possible to rank all efficient DMUs. Here, in the output oriented DEA model we proposed an Andersen-Petersen equivalent super-efficient DEA model by eliminating all the terms associated with a particular efficient DMU in all constraints when evaluating that particular DMU such that (1)-(3) become

$$
\text { Maximize } \quad \Omega_{E}
$$

subject to

$$
\begin{gathered}
-X_{0 i}+\sum_{k \neq E}^{S} X_{k i} \lambda_{k}=0, i=1,2 \ldots n, \\
-Y_{0 j} \Omega_{0}+\sum_{k \neq E}^{S} Y_{k j} \lambda_{k} \geq 0, j=1,2 \ldots m, \\
\lambda_{k} \geq 0, k=1,2, \ldots, S,
\end{gathered}
$$

$\Omega_{E}$ unconstrained,

$\mathrm{DMU}_{E}$ is an efficient DMU. This will produce a score of 0 $<\Omega_{E} \leq 1$, giving super-efficiency score of $\theta_{E} \geq 1$, making it possible to rank efficient DMUs. The scores for inefficient DMUs remain unchanged.

\section{EMPIRICAL IMPLEMENTATION}

DEA Input and Outputs: The sample addressed in the study relates to selected listed companies in Malaysia. The basic data are obtained from Malaysian Business magazine [18] for financial year end that falls on or before July 31. Only companies which have been listed at Bursa Malaysiafor at least two years are surveyed. Their financial performance are broken down into six sub-listings including turnover (or revenue), net profit, equity and assets. However, no information is furnished on input factors relating to labour, capital and expenditure. A total of 114 companies comprising of 20 GLCs and 94 non-GLCs were selected based on their revenues.

Table I summarizes the descriptive statistics. All indicators show an increasing trend. The average revenue, profit, equity 
and assets grow at a rate of approximately 6.60, 30.10, 19.30 and 16.50 percent per annum respectively. A GLC conglomerate Sime Darby dominates the top revenue generator for all years but the top earner in terms of profit earned is another GLC financial institution, Malayan Banking which also accumulates the largest asset for all the years. At RM25657.2 million, a GLC power supplier TNB tops the equity list in 2009, but loses to Malayan Banking for the next two years. On the less fortunate side, a non-GLC Lion Corporationis the biggest loser at RM-1215.50 million in 2009 and RM-281.1 million in 2011. Another non-GLC loser is Zelan at RM-275.0 million in 2010 and generating the lowest revenue in 2011 at RM41.4 million.

TABLE I:DESCRIPTIVE STATISTICS FOR 2009-2011 (RM MILLION)

\begin{tabular}{|r|l|r|r|r|r|}
\hline Year & Variables & \multicolumn{1}{|c|}{ Mean } & Std. Dev & \multicolumn{1}{c|}{ Maximum } & Minimum \\
\hline 2009 & Revenue & 4571.2 & 5164.4 & 32028.0 & 559.1 \\
& Profit & 372.9 & 651.2 & 3002.3 & -1215.5 \\
& Equity & 3277.8 & 4701.8 & 25657.2 & 121.0 \\
& Asset & 15758.4 & 38384.0 & 268910.9 & 425.3 \\
\hline 2010 & Revenue & 4672.9 & 5366.1 & 33819.5 & 755.1 \\
& Profit & 466.7 & 649.4 & 3968.5 & -275.0 \\
& Equity & 3788.2 & 5469.9 & 27877.2 & 156.8 \\
& Asset & 18013.5 & 45459.5 & 332219.1 & 518.8 \\
\hline 2011 & Revenue & 5190.4 & 6294.8 & 42872.0 & 41.4 \\
& Profit & 631.7 & 916.9 & 4619.8 & -281.1 \\
& Equity & 4666.8 & 6609.6 & 32470.3 & 0.6 \\
& Asset & 21338.7 & 54791.6 & 405449.6 & 532.6 \\
\hline
\end{tabular}

One input and six output indicators are chosen to characterize and reflect the diverge performance of the companies. These indicators are defined as follows,

- Input $(X)$ : Total operating expenditure (or cost), approximated as revenue less net profit.

- Output $1(Y 1)$ : The rate of change of revenue, expressed in percentage.

- Output 2 (Y2): The rate of change of net profit, expressed in percentage.

- Output 3 (Y3): The rate of change of assets, expressed in percentage.

- Output 4 (Y4): The return on revenue, expressed in percentage.

- Output 5 (Y5): The return on equity, expressed in percentage.

- Output 6 (Y6): The return on assets, expressed in percentage.

The single input, total operating expenditure denotes the business operational costs of materials and labour to generate products or to provide the services. This may include salary and wages for the employees, office rentals, maintenance costs and others. However, no information is furnished on these items and we approximate it as revenue less net profit. The first three output measures capture the dynamicity of the performance while the next three measures capture the profitability ratios, normally equated with the company's ability to generate a return on its resources.

All the six output measures take on negative values for some observations and DEA is not capable of handling negative data. Thus for consistency, all indicators (including input) are normalized on a scale of $[1,100]$ such that

$$
X_{\text {nor }}=\frac{99\left(X_{a c t}-X_{\min }\right)}{X_{\max }-X_{\min }}+1
$$

where $X_{n o r}$ is the value of the normalized indicator, $X_{a c t}$ is the actual value of the indicator; $X_{\max }$ is the maximum value of the indicator; $X_{\min }$ is the minimum value of the indicator.

This transformation ensures that $X_{\text {nor }} \in[1,100]$, and is synonymous with United Nation Human Development Index.

DEA Results and Interpretations:We used linear programming software LINDO to solve the strictly output-oriented super-efficient DEA model under the assumptions of CRS and VRS. This amounts to solving 228 linear programming problems. The efficiency scores are interpreted as a measure of comparative performance of the units under investigation. It provides information on how each individual company performed in comparison with other companies for the year under consideration.

\section{A. Technical Efficiency}

The results for the top and bottom tenunder the assumption of CRS is presented in Table II. Sevennon-GLCsare considered super-efficient in at least one year under the assumption of CRS. These are PBB Group, Kwantas Corporation, QSR Brands, Press Metal, Media Prima, General Corporation and Keck Seng (M). None is super-efficient in all years. Only four averaged as super-efficient. None of the GLCs are considered relatively efficient under CRS. As depicted in Table II, with the exception of PBB Group the top companies ranked by DEA comprises of lower ranked companies by revenue. These top performers obtain an average relative technical efficiency of greater than seventy-eight percent. Only two are GLCs, namely Syarikat Takaful Malaysia, an Islamic insurance company and Malaysia Airport Holdings. An interesting observation is that thebottom performers are from top companies by revenue except Maxis. In fact the bottom-five are the top-five by revenue and are GLCs main income generators. The technical efficiency score for inefficient units under CRS range from 0.13941 to 0.88819 . The overall average is 0.58561 with GLCs and non-GLCs averaging 0.54104 and 0.59509 respectively.

TABLE II: TECHNICAL EFFICIENCY SCORES, 2009-2011

\begin{tabular}{|l|l|l|l|l|}
\hline \multicolumn{1}{|c|}{ Company } & 2009 & 2010 & 2011 & Average \\
\hline PBB Group & 0.19586 & 2.71779 & 1.44226 & 1.45197 \\
\hline QSR Brands & 1.66583 & 1.50592 & 0.52814 & 1.23330 \\
\hline Press Metal & 2.01644 & 0.83419 & 0.69049 & 1.19037 \\
\hline $\begin{array}{l}\text { Kwantas } \\
\text { Corporation }\end{array}$ & 0.49005 & 0.57083 & 1.97151 & 1.01080 \\
\hline Keck Seng (M) & 0.55902 & 0.75323 & 1.35231 & 0.88819 \\
\hline Media Prima & 0.67898 & 1.31626 & 0.66600 & 0.88708 \\
\hline General Corporation & 1.17225 & 0.74839 & 0.57516 & 0.83194 \\
\hline $\begin{array}{l}\text { Syarikat Takaful } \\
\text { (M)* }\end{array}$ & 0.85543 & 0.71554 & 0.83460 & 0.80185 \\
\hline Malaysia Airport * & 0.69316 & 0.79541 & 0.89743 & 0.79533 \\
\hline Carlsberg Brewery & 0.83655 & 0.75263 & 0.76319 & 0.78412 \\
\hline \multicolumn{1}{|c|}{$:$} & & & & \\
\hline Shell Refining Co. & 0.21674 & 0.39806 & 0.60046 & 0.40509 \\
\hline IOI Corporation & 0.35747 & 0.35384 & 0.50079 & 0.40403 \\
\hline Lion Corporation & 0.31750 & 0.43923 & 0.44667 & 0.40113 \\
\hline UMW Holdings * & 0.27859 & 0.35038 & 0.56237 & 0.39711 \\
\hline Maxis & 0.36918 & 0.38931 & 0.42618 & 0.39489 \\
\hline Malayan Banking * & 0.25098 & 0.36821 & 0.41976 & 0.34632 \\
\hline MISC * & 0.22734 & 0.27245 & 0.53812 & 0.34597 \\
\hline PetronasDagangan * & 0.12475 & 0.17946 & 0.28578 & 0.19666 \\
\hline TenagaNasional * & 0.12285 & 0.17876 & 0.22554 & 0.17572 \\
\hline Sime Darby * & 0.09901 & 0.13830 & 0.18093 & 0.13941 \\
\hline Government Linked Companies, GLCs. & & \\
\hline
\end{tabular}




\section{B. Pure Technical Efficiency}

The VRS efficiency scores measure pure technical efficiency $(P T E)$ excluding the effects of scale operations and are more encouraging. They are greater than the corresponding CRS efficiency scores. Only two companies, Press Metal and British American Tobacco (M), both non-GLCs exhibit super-efficiency in all years. Sixteen more companies(one GLC, Sime Darby, and fifteen non-GLCs) achieve super-efficient score in at least one year. Seven companies are also efficient under CRS, thereby implying that they are also $100 \%$ scale efficient in at least one of the years under evaluation.Six of the financial institutions (three from each group) namely Malayan Banking, BIMB Holdings, CIMB Holdings, Hong Leong Financial Group, Hong Leong Bank and Public Bank join the top thirty percent DEA ranking. The average for the three years is 0.78636 , 0.90731 and 0.98232 respectively, indicating a significant increasing trend. The overallgroup average is 0.89200 with GLCs and non-GLCs averaging 0.84983 and 0.90097 respectively. However, the minimum average PTE score by GLCs is 0.79028 , higher than the minimum average score by non-GLCs of 0.69683 .

TABLE III:MEAN EFFICIENCY GLCS AND NON-GLCS, 2009-2011
\begin{tabular}{|l|c|c|c|}
\hline & TE & PTE & SE \\
\hline All companies & 0.58561 & 0.89200 & 0.66386 \\
Maximum & 1.45197 & 1.82110 & 0.91828 \\
Minimum & 0.13941 & 0.69683 & 0.17101 \\
\hline GLCs_average & 0.54104 & 0.84983 & 0.62685 \\
Maximum & 0.80185 & 0.93995 & 0.91828 \\
Minimum & 0.13941 & 0.79028 & 0.17101 \\
\hline Non-GLCs_average & 0.59509 & 0.90097 & 0.67046 \\
Maximum & 1.45197 & 1.82110 & 0.86454 \\
Minimum & 0.39489 & 0.69683 & 0.42410 \\
\hline
\end{tabular}

\section{Scale Efficiency}

The ratio of CRS and VRS efficiency is the scale efficiency ( $S E=T E / P T E)$. This is reported in Table III. The fourteen VRS-efficient units are not able to register best business performance scores because of limitations of their scale and operation. Seven companies are 100 percent scale efficient in at least one of the years under evaluation, thereby putting them on the frontier of the most productive scale size, mpss. No company (GLCs or non-GLCs) is 100 percent scale efficient in all the years. It is interesting to note that eight of the GLCs $(40.0 \%)$ achieve scale efficiency of less than 50.0 percent as compared to four of the non-GLCs (4.26\%). The bottom-five are all GLCs namely, Sime Darby, TenagaNasional, PetronasDagangan, Malayan Banking and MISC.

Table IIIalso provides a summary of the average efficiency scores and the relative efficiency ranges for GLCs and non-GLCs. Results under VRS are more encouraging. The inefficient scores range from 0.69683 to 0.97597 . Almost all of the companies investigated achieve a pure technical efficiency score of more than 70.0 percent. None of the company's PTE scores falls below 69.0 percent. The distribution of $S E$ score is slightly better than that of $T E$ with higher average score of 0.66386 and shorter range.. The scores for inefficient units vary in a range of $0.17101-0.91828$ for the GLCS and $0.42410-0.86454$ for the non-GLCs. Fifty-five percent of the GLCs and 37.23 percent of the non-GLCs are more than $70.0 \%$ scale efficient. Thus, it seems that most companies appeared to be facing serious scale inefficiency.

\section{Returns to Scale}

Apart from the inefficiencies that could arise in the conversion process, another reason for the inefficiencies of the inefficient units could be attributed to the scale of operations. DMUs that do not operate at the most efficient (or productive) scale size cannot be fully efficient. The inefficiency may arise because it is operating under DRS or IRS. A DMU is said to be operating under DRS if changing all inputs by the same proportion results in a smaller proportional change in outputs. IRS may also be defined similarly. Whether a DMU is operating under IRS or DRS can be determined by observing its $T E$ and PTE efficiency scores, such that

- if $T E=P T E$, CRS prevails

- if $T E \neq P T E$, then

$$
\left\{\begin{array}{l}
\sum_{k=1}^{S} \lambda_{k}<1 \rightarrow \text { IRS. } \\
\sum_{k=1}^{S} \lambda_{k}>1 \rightarrow \text { DRS }
\end{array}\right.
$$

In our analysis only seven performers, operating under CRS are $100 \%$ scale efficient, in at least one year, thereby implying the existence of multiple most productive scale size. The remainder DMUs all exhibit DRS. This suggests that most companies not only show serious scale inefficiency, but also operate in a region of DRS. None of the company is operating in an IRS region. Hence it may be concluded that one reason for the inefficiency of these companies (GLCs and non-GLCs) comes from its scale size. It is operating under DRS leading to the fact that any increase in input results in less than proportionate increase in outputs or improvement in performance.

\section{CONCLUSION}

The study utilizes a strictly output oriented super-efficiency DEA methodology to assess the performance of selected largest listed companies in Malaysia based on multi-dimensional performance indicators under the assumptions of CRS and VRS. One input and six output indicators reflecting the business dynamicity and profitability achievements are used for the evaluation. A linear transformation is adopted to handle the negative data such that all indicators lie between 1.0 and 100 .

Results obtain suggest that only $3.5 \%$ and $12.3 \%$ are found to be relatively efficient under CRS and VRS respectively. None of the GLCs is efficient under CRS. However, only $6 \%$ are $100 \%$ scale efficient with multiple most productive scale size in at least one of the years under evaluation. None is $100 \%$ scale efficient in all years. These top performers are from revenue-bottom-ranked companies, mainly non-GLCs. Thus, revenue-top-ranked companies (mainly GLCs) are not necessarily top-ranked performers. The VRS test suggests that the nonperformers are operating in the region of DRS. 
These findings are in agreement with findings by Zhu [19]. However, the study found no company is operating in the region of IRS.

Like any other performance or efficiency evaluation technique, DEA has several limitations. DEA efficiency scores are sensitive to sample size and input-output mix. Future studies should focus on larger sample size and experiment with different input-output mix to test the robustness of the results. Efficiency or performance gives more meaning when it is assessed over time. Given a set of panel data the Malmquist total factor productivity, TFP change index technique can be utilized to explore the dynamicity of companies. This provides avenue for future research.

\section{REFERENCES}

[1] R. A. Collins, "An empirical comparison of bankruptcy prediction model," Financial Management., vol. 9, no. 2, pp. 52-57, Summer 1980.

[2] P. Espahbodi, "Identification of problem banks and binary choice model," Journal of Banking and Finance, vol. 15, no. 1, pp. 53-71, Feb. 1991.

[3] R. S. Kaplan and D. P. Norton, "Using the balanced scorecard as a strategic management system," Harward Business Review, vol. 76, no. 1, pp. 75-85, Jan-Feb. 1996.

[4] R. J. Vokurka, "Operationalising the balanced scorecard using theMalcolm Baldrige Criteria for Performance Excellence (MBCPE)," International Journal of Management and Enterprise Development, vol. 1, no. 3, pp. 208-217, Sept. 2004.

[5] G. J. Fielding, T. T. Babitsky, and M. E. Brenner, "Performance evaluation for bus transit," Transportation Research, vol. 19, no. 11, pp. 73-82, Feb. 1985.

[6] W. Y. Liang, "The analytic hierarchy process in project evaluation: an R\&D case study in Taiwan," Benchmarking: An International Journal, vol. 10 , no. 5, pp. 445-456, Oct. 2003.

[7] W. Tsai, P. Y. Hsu, J. M. Cheng, and Y. Chen, "An AHP approach to assessing the relative importance weights of ERP performance measure," International Journal of Management and Enterprise Development, vol. 3, no. 4, pp. 351-375, Feb. 2006.

[8] T. S. Felix and H. J. Chan, "An innovative performance measurement method for supply chain management," Supply Chain Management: An International Journal, vol. 8, no. 3, pp. 209-223, June 2003.

[9] C. T. Ho, "Measuring bank operations performance: an approach based on grey relation analysis," Journal of the Operational Research Society,vol. 57, no. 4, pp. 337-349, April 2006.

[10] N. H. Mohamad and F. Said, "Measuring the performance of 100 largest listed companies in Malaysia," African Journal of Busines Management, vol. 4, no. 13, pp. 3178-3190, Oct. 2010.
[11] L. M. Seiford and J. Zhu, "Profitability and marketability of the top 55 US commercial banks," Management Science, vol. 45, no. 9, pp 1270-1288, Sept. 1999.

[12] M. Al-Shammari, "Optimization modelling for estimating and enhancing relative efficiency with application to industrial companies," European Journal of Operational Research, vol. 115, no. 3, pp. 488-496, June 1999.

[13] M. M. Mostafa, "Evaluating the comparative market efficiency of top listed companies in Egypt," Journal of Economic Studies, vol. 34, no. 5, pp. 430-452, Oct. 2007.

[14] C. B. Ho and K. B. Oh, "Measuring online stock broking performance," Industrial Management and Data Systems, vol. 108, no. 7, pp. 988-1004, Oct. 2008.

[15] H. Chen, "Stock selection using data envelopment analysis," Industrial Management and Data Systems, vol. 108, no. 9, pp. 1255-1268, Dec. 2008.

[16] S. Ebadi, G. R. Jahanshahloo, and F. Aliev, "A method for ranking efficient DMUs," Australian Journal of Basic and Applied Sciences, vol. 5, no. 11, pp. 91-97, Nov. 2011.

[17] P. Andersen and N.C. Petersen, "A procedure for ranking efficient units in data envelopment analysis," Management Science, vol. 39, no. 10, pp. 1261-1264, Oct. 1993.

[18] Malaysian Business, Various Issues, October $16^{\text {th }}-31^{\text {st }}, 2009,2010$ and 2011,Berita Publishing Sdn. Bhd., ISSN, 0126-5504.

[19] J. Zhu, "Multi-factor performance measure model with an application to Fortune 500 companies," European Journal of Operational Research, vol. 123, no. 1, pp. 105-124, May 2000.

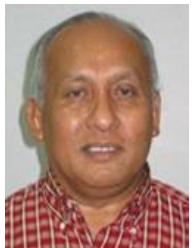

N. H. Mohamad was born in Malaysia in 1954. He received his B. Sc. (Hons.) majoring in applied mathematics from Queen Mary College, University of London in 1977 and M. Sc. in Mathematics from the University of London in 1978. In 1990 he received his $\mathrm{Ph}$ $\mathrm{D}$ in Systems Science from the City University, London.He is currently an associate professor with the Institute of Mathematical Sciences, University of Malaya, Malaysia. His research interests include applied operational research, management science and mathematical programming. He has published many papers on data envelopment analysis in ISI /SCOPUS Cited journals.He is a member of the Management Science/Operational Research Society of Malaysia (MS/OR).

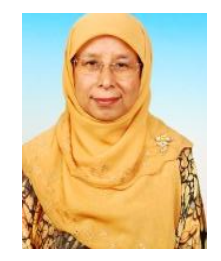

F. Said was born in Malaysia in 1953. She received her B. Econ. (Hons) majoring in applied economics from the University of Malaya, Malaysia in 1976 and M. Sc. in economics from Queen Mary College, University of London in 1978. She is a retired associate professor from the Faculty of Economics and Administration, University of Malaya. Currently she holds a post as Research Fellow at the same institute. Her interests include applied economics and data envelopment analysis. She has published many papers on data envelopment analysis in ISI /SCOPUS Cited journals. 